\title{
Contextual knowledge reduces demands on working memory during reading
}

\author{
LISA M. SOEDERBERG MILLER \\ University of California, Davis, California \\ and \\ JASON A. COHEN and ARTHUR WINGFIELD \\ Brandeis University, Waltham, Massachusetts
}

\begin{abstract}
An experiment is reported in which young, middle-aged, and older adults read and recalled ambiguous texts either with or without the topic title that supplied contextual knowledge. Within each of the age groups, the participants were divided into those with high or low working memory (WM) spans, with available WM capacity further manipulated by the presence or absence of an auditory target detection task concurrent with the reading task. Differences in reading efficiency (reading time per proposition recalled) between low WM span and high WM span groups were greater among readers who had access to contextual knowledge relative to those who did not, suggesting that contextual knowledge reduces demands on WM capacity. This position was further supported by the finding that increased age and attentional demands, two factors associated with reduced WM capacity, exaggerated the benefits of contextual knowledge on reading efficiency. The relative strengths of additional potential predictors of reading efficiency (e.g., interest, effort, and memory beliefs), along with knowledge, WM span, and age, are reported. Findings showed that contextual knowledge was the strongest predictor of reading efficiency even after controlling for the effects of all of the other predictors.
\end{abstract}

Theoretical arguments, as well as intuition, suggest that the more we know about a particular topic, the easier it is for us to understand and remember texts drawing on this knowledge (e.g., Ericsson \& Kintsch, 1995; Vicente \& Wang, 1998). For example, when one buys a new cell phone to replace an older one, one can read the procedure for setup fairly quickly because one can draw on prior knowledge of how to perform these operations. With prior knowledge, not only can one read these new instructions more quickly, but one can also remember their content more accurately than if one did not have this prior knowledge.

A considerable amount of research has shown that knowledge supports reading comprehension and memory for text (e.g., Adams, Bell, \& Perfetti, 1995; Chiesi, Spilich, \& Voss, 1979; Means \& Voss, 1985; Moravcsik \& Kintsch, 1993; Rawson \& Kintsch, 2002; Spilich, Vesonder, Chiesi, \& Voss, 1979; Summers, Horton, \& Diehl, 1985; Taylor,

This research was supported by NIH Grant AG19196 to L.M.S.M and by NIH Grant AG04517 to A.W. The authors gratefully acknowledge support from the W. M. Keck Foundation. The authors also thank Jennifer Weisman, Igor Barshtyen, and Heather Ridolfo for their help with data collection, Elizabeth Stine-Morrow for helpful discussions and comments on an earlier draft of the manuscript, and Michael Kane and two anonymous reviewers for additional helpful suggestions. Address correspondence to L. M. Soederberg Miller, Department of Human and Community Development, University of California, Davis, CA 95616 (e-mail: lmsmiller@ucdavis.edu).

Note-This article was accepted by the previous editorial team, when Colin M. MacLeod was Editor.
1979; Voss, Vesonder, \& Spilich, 1980). In addition, there is evidence that knowledge reduces the time required to process the text as measured by reading speed (Kaakinen, Hyönä, \& Keenan, 2003; Miller \& Stine-Morrow, 1998; Sharkey \& Sharkey, 1987; Smith \& Swinney, 1992; Wiley \& Rayner, 2000). To the extent that prior knowledge allows an individual to both read a text more quickly and recall more of what has been read, one can describe the knowledgeable reader as being more efficient.

Knowledgeable readers make implicit decisions regarding time allocated to the text and the resulting memory representation-essentially, a speed-accuracy trade-off (see Carver, 1990). For example, one knowledgeable reader may allocate a good deal of time in order to obtain an exceptional memory representation, whereas another may prefer to read more quickly and settle for an average memory representation. Both of these individuals, however, will have greater reading efficiency relative to the individual who lacks relevant background knowledge. Individuals without the benefits of knowledge will be faced with similar trade-off decisions but will undoubtedly have to spend more time reading and still will not be able to achieve the crisp memory representation of their high-knowledge counterparts. We were interested in examining the effects of knowledge on such trade-offs. Formally, we define reading efficiency as the amount of time spent reading a text per unit of information recalled (see Hartley, Stojack, Mushaney, Annon, \& Lee, 1994; Meyer, Talbot, \& Florencio, 1999; and Stine \& Hindman, 1994, for similar approaches). 
The primary goal of the present study was to elucidate the effects of contextual knowledge on reading efficiency. Contextual knowledge is information regarding the general content or framework (e.g., schema or script) of a text. An example of a reading situation in which the reader does not have the benefit of contextual knowledge to facilitate comprehension is when an individual picks up a magazine while waiting at the doctor's office and begins reading a passage in midsection. Bransford and Johnson (1972) nicely demonstrated the power of contextual knowledge in their study in which they manipulated the presence of passage titles prior to reading. They found strong effects of prior context on subsequent recall. We wanted to extend this finding in several ways. First, we wanted to assess the effects of contextual knowledge on speed-accuracy tradeoffs during reading (i.e., reading efficiency). Second, we wanted to determine whether contextual knowledge reduces demands on working memory (WM). We approached these questions using two variables that purportedly affect availability of WM: adult age and divided attention, both of which are described in greater detail below.

Another goal of the present study was to examine the role of motivation in how efficiently individuals read. Several studies have shown that motivational influences, such as passage interest (Lin, Zabrucky, \& Moore, 1997), reading effort (Walker, Jones, \& Mar, 1983), and cognitive control beliefs (Miller \& Gagne, 2005; Stine, Lachman, \& Wingfield, 1993), are important predictors of comprehension and memory performance. However, we know of none that has investigated the effects of motivation on reading efficiency. We were particularly interested in determining whether motivational factors would be able to predict reading efficiency after taking into account the reader's prior knowledge of the context.

Reading involves extracting meaning from orthographic symbols. According to Kintsch (1994), readers select segments of text and input them into WM in cycles such that multiple operations can be performed on the input. For example, readers decode letters, identify words, access the meaning of these words, and assign thematic roles to the words in order to form syntactic units. These units represent ideas, or propositions, which then must be organized within a sentence and integrated across sentences in order to form a textbase representation. Readers also construct a notion of what the text refers to, beyond the literal words printed on the page. This type of representation is typically called a situation model (van Dijk \& Kintsch, 1983) or a mental model (Johnson-Laird, 1983).

Each of the above reading operations is thought to place some demand on WM (e.g., Kintsch, 1994), which is typically defined as a limited-capacity system that both stores and manipulates information (e.g., Baddeley \& Hitch, 1974; Daneman \& Carpenter, 1980; Engle, 2001). One way that prior contextual knowledge could make reading more efficient is by reducing demands on WM. If this is the case, readers armed with this knowledge should be able to do more (i.e., achieve greater efficiency) with less (smaller WM capacity). Here, we consider the specific postulate that prior knowledge could compensate for conditions in which there is a reduced WM capacity (e.g., Adams et al., 1995; Taylor, 1979; West, Stanovich, \& Cunningham, 1995). To the extent that knowledge facilitates lexical access, organizational and integration processes, and construction of a situation model, knowledge should reduce demands on WM. Conversely, without contextual knowledge, the reader would have to rely more on WM in order to hold and manipulate verbal material that lacked clear meaning and organization.

In the present study, we compared reading efficiency of readers who differed in WM spans and who either were or were not given prior knowledge of the topic of a text to be read. If knowledge reduces demands on WM, then differences in reading efficiency between WM span groups should exist among readers without access to prior contextual knowledge but should be smaller, if not disappear, among readers with access to such knowledge.

To further test the hypothesis that knowledge reduces demands on WM while reading, we varied two additional factors. First, we included middle-aged adults, older adults, and younger adults, because a good deal of evidence suggests that WM capacity declines with age (Salthouse, 1991; Wingfield, Stine, Lahar, \& Aberdeen, 1988). Although aging represents more than declines in WM, these declines represent a major feature of age-related cognitive change. Several researchers have reasoned that, due to age-related declines in WM, knowledge could be more important with increasing age (e.g., Arbuckle, Vanderleck, Harsany, \& Lapidus, 1990; Hultsch \& Dixon, 1983; Miller, 2001, 2003; Miller \& Stine-Morrow, 1998; Miller, Stine-Morrow, Kirkorian, \& Conroy, 2004; Morrow, Leirer, \& Altieri, 1992; Morrow, Leirer, Altieri, \& Fitzsimmons, 1994).

Second, for all age groups, we included a dividedattention condition that required the participants to perform a distractor task while reading. This condition would be expected to place greater demands on WM because individuals would be attempting to perform two tasks at once. Thus, both increased age and dividing attention would be expected to place additional constraints on WM and would therefore increase the opportunity for knowledge to have beneficial effects on reading efficiency.

As previously indicated, we also examined motivational predictors that might influence participants' reading efficiency. The motivational predictors were chosen on the basis of prior work on reading and motivation in both children (Guthrie \& Wigfield, 1999) and adults (Dunlosky $\&$ Hertzog, 1998). These were the relatively stable motivational factors of need for cognition (Cacioppo, Petty, \& Kao, 1984) and memory control beliefs (Lachman, Bandura, Weaver, \& Elliott, 1995), as well as task-specific factors of self-ratings of interest, enjoyment, effort, and engagement relative to the passages. Our specific question was whether individual differences in these motivational factors would predict reading efficiency above and beyond effects of knowledge, WM, and age.

\section{Overview of Experiment and Predictions}

In the present experiment, the participants read passages of the sort used by Bransford and Johnson (1972) that were vague, ambiguous, and difficult to understand 
but that would be much clearer if the topics of the passages were known beforehand. For example, a portion of one passage taken from Bransford and Johnson's study on the effects of prior contextual knowledge on memory for passages was, "It is important not to overdo any particular endeavor. That is, it is better to do too few things at once than too many." Readers who had been given the passage title "Washing Clothes" understood that these sentences referred to the importance of separating laundry into appropriately sized loads in order to avoid damaging the clothes or the washing machine. Thus, those who received passage titles prior to reading had access to the contextual knowledge (framework or schema) that enabled them to easily understand the texts. Those who were not given the titles, read without the benefit of this knowledge.

In addition to the above knowledge manipulation (presence or absence of passage titles) and the presence or absence of a secondary task while reading, the young, middle-aged, and older adults were divided into those with high versus low WM spans for their age group. This was accomplished by taking a median split on scores within each age group on a verbal WM span task (Daneman \& Carpenter, 1980).

The passages were presented clause by clause on a computer screen. The rate of presentation was controlled by the participant, who pressed the space bar on the computer keyboard to deliver each clause. Clause reading times were measured as the time from stimulus onset to keypress. After reading the entire passage, the participants recalled the content of the passage as accurately as possible. Reading efficiency was assessed by dividing the average clause reading time by the number of idea units recalled for each passage when read with or without prior contextual knowledge, with or without a concurrent divided-attention task, for the young, middle-aged, and older adults with high or low WM spans relative to their respective age group.

Our core prediction was that contextual knowledge would increase reading efficiency by reducing demands on WM capacity. This would be supported by (1) increased reading efficiency among readers given prior contextual knowledge relative to those not given this knowledge and (2) larger differences in reading efficiency between high and low WM span groups among readers without prior knowledge than among readers with prior knowledge. To the extent that contextual knowledge reduces demands on WM, we also expected that the benefits of knowledge would be particularly evident within the divided-attention condition and among middle-aged and older adults relative to the young adults.

Although our primary focus was on the postulated interplay of contextual knowledge and WM capacity on reading efficiency, one might also expect motivational factors to play an additional role in reading performance. To the extent that such factors as passage interest (Lin et al., 1997), perceived effort (Walker et al., 1983), and cognitive control beliefs (Miller \& Gagne, 2005) affect comprehension and memory performance, one might expect a similar effect on reading efficiency in addition to the effects of contextual knowledge and available WM resources. We also expected to find that motivation would be a powerful predictor of reading efficiency but did not make explicit predictions as to which motivation predictors would be able to account for variance above and beyond the effects of knowledge.

\section{METHOD}

\section{Participants}

The participants were 100 young (ages $18-34$ years, $M=25.82$, $S D=4.17$ ), 100 middle-aged (ages 35-59 years, $M=48.20, S D=$ 7.30 ), and 100 older (ages $60-85$ years, $M=69.27, S D=6.04$ ) adults. The participants were recruited from advertisements in the Boston area and were given monetary compensation for their time. Only native speakers of English were allowed to participate, and none reported any history of neurological disease that might impair cognitive performance.

The participants within each age group were randomly assigned to either a title or a no-title group that was determined by providing or withholding passage titles, respectively. The participants within each of these groups were further divided into those with high and low WM spans, as described next.

To assign the participants to a high or low WM group, we assessed WM span using a loaded sentence span task (Daneman \& Carpenter, 1980; Stine \& Hindman, 1994), which has been shown to be related to performance on language tasks (Daneman \& Merikle, 1996). We acknowledge that this task relies on language and therefore may show relationships to language tasks that may be overestimated relative to WM tasks that do not rely on language. For this task, the participants were required to respond "true" or "false" to an increasingly larger set of sentence statements. After reading a set of sentences, the participants were required to repeat the list of sentence-final words from that set in correct order. The final score was the number of words correctly recalled at the highest level attained (for more details, see Stine \& Hindman, 1994). This task was chosen because it draws heavily on both storage and processing components of WM (Daneman \& Carpenter, 1980; Daneman \& Merikle, 1996). The participants were assigned to a WM span group through a median split within each age group such that those who were below the median comprised the low WM span group and those who were above the median comprised the high WM span group.

Table 1 contains the means and standard deviations for the ages, years of education, vocabulary, and WM span for each of the age, knowledge, and WM span groups. Vocabulary was assessed by the Extended Range Kit of Factor-Referenced Cognitive Tests (Ekstrom, French, \& Harman, 1976). This is a multiple-choice vocabulary test with two 18-item sections, each with a time limit of $4 \mathrm{~min}$.

To ensure that those assigned to the title and no-title groups were similar in their characteristics, we separately analyzed education level, vocabulary score, and WM span in three 2 (title: absent, present) $\times 2$ (WM span group: low, high) $\times 3$ (age: young, middle, old) ANOVAs. There were no main effects of title on education, vocabulary, and WM span, indicating that the randomly assigned title and no-title groups were comparable in these regards. As expected, the participants showed typical age-related differences in WM capacity and vocabulary. Specifically, there was an age-related decrease in WM capacity $[F(2,288)=43.85, p<.001]$ and an age-related increase in vocabulary $[F(2,288)=17.59, p<.001]$. A main effect of age on education $[F(2,288)=3.51, p<.05]$ was qualified by a significant age $\times \mathrm{WM}$ span group interaction $[F(2,288)=3.82$, $p<.05$ ], showing lower education levels among low relative to high WM span participants among the middle-aged and older adults but comparable education levels among low and high WM span younger adults. No other interactions were significant.

\section{Materials}

Passages. Six passages were used as stimuli. Two were taken from Bransford and Johnson (1972; "Washing Clothes," "Making and Flying a Kite"), two were taken from Dooling and Lachman (1971; "Christopher Columbus," "First Space Voyage"), one was taken from Gardner and Schumacher (1977; "Attack of Viruses"), 
Table 1

Means and Standard Deviations of Background Measures Within Title (Contextual Knowledge), WM Span, and Age Groups

\begin{tabular}{|c|c|c|c|c|c|c|c|c|c|c|c|c|c|}
\hline & & \multicolumn{6}{|c|}{ No Title (No Contextual Knowledge) } & \multicolumn{6}{|c|}{ Title (Contextual Knowledge) } \\
\hline & & \multicolumn{3}{|c|}{ Low WM Span } & \multicolumn{3}{|c|}{ High WM Span } & \multicolumn{3}{|c|}{ Low WM Span } & \multicolumn{3}{|c|}{ High WM Span } \\
\hline & & $\begin{array}{c}\text { Young } \\
n=28\end{array}$ & $\begin{array}{l}\text { Middle } \\
n=20\end{array}$ & $\begin{array}{c}\text { Older } \\
n=22\end{array}$ & $\begin{array}{l}\text { Young } \\
n=22\end{array}$ & $\begin{array}{l}\text { Middle } \\
n=30\end{array}$ & $\begin{array}{c}\text { Older } \\
n=28\end{array}$ & $\begin{array}{r}\text { Young } \\
n=22\end{array}$ & $\begin{array}{l}\text { Middle } \\
n=23\end{array}$ & $\begin{array}{c}\text { Older } \\
n=25\end{array}$ & $\begin{array}{c}\text { Young } \\
n=28\end{array}$ & $\begin{array}{l}\text { Middle } \\
n=27\end{array}$ & $\begin{array}{c}\text { Older } \\
n=25\end{array}$ \\
\hline \multirow[t]{2}{*}{ Age } & $M$ & 26.61 & 46.75 & 70.55 & 25.41 & 49.67 & 67.57 & 26.09 & 49.48 & 70.72 & 25.14 & 46.56 & 68.60 \\
\hline & $S D$ & 4.49 & 8.43 & 6.41 & 4.09 & 7.57 & 5.17 & 3.91 & 6.56 & 6.95 & 4.15 & 6.48 & 5.37 \\
\hline \multirow[t]{2}{*}{ Education } & $M$ & 16.64 & 15.05 & 16.09 & 16.95 & 16.57 & 17.71 & 16.82 & 15.26 & 15.80 & 16.32 & 16.81 & 17.76 \\
\hline & $S D$ & 2.64 & 3.17 & 2.58 & 2.54 & 1.77 & 3.55 & 2.44 & 2.16 & 2.87 & 2.52 & 2.37 & 2.18 \\
\hline \multirow[t]{2}{*}{ Vocabulary } & $M$ & 15.00 & 16.46 & 20.92 & 20.16 & 24.67 & 26.56 & 15.85 & 19.01 & 23.09 & 18.64 & 23.22 & 25.58 \\
\hline & $S D$ & 8.17 & 9.20 & 6.94 & 7.73 & 8.21 & 8.02 & 6.55 & 8.66 & 7.83 & 6.88 & 8.30 & 7.39 \\
\hline \multirow[t]{2}{*}{ WM span } & $M$ & 4.55 & 3.23 & 3.13 & 6.51 & 5.95 & 5.77 & 4.43 & 3.84 & 3.17 & 6.56 & 5.82 & 5.36 \\
\hline & $S D$ & 0.70 & 0.65 & 0.85 & 0.87 & 1.06 & 1.19 & 0.68 & 0.56 & 0.87 & 0.74 & 1.12 & 0.91 \\
\hline
\end{tabular}

Note-WM, working memory.

and one was taken from Miller and Stine-Morrow (1998; "Driving a Car"). Each of these passages contained empty nouns and ambiguous phrases that rendered the passage difficult to understand if it was not preceded by a title that supplied the topic of the passage. The titles provided knowledge necessary to easily understand the contents of the passage. Passages ranged between 77 and 162 words in length. Passages were segmented into clauses; there was a mean of 29.8 clauses per passage $(S D=6.2)$.

Motivational measures. Four motivational factors were assessed for each participant: need for cognition, memory controllability beliefs, interest/enjoyment, and effort/engagement. The short version (18 items) of the Need for Cognition (NFC) scale (Cacioppo et al., 1984) was used to assess propensity to engage in cognitive tasks. The participants indicated the extent to which they agreed with statements such as "I find satisfaction in deliberating hard for long hours." We found adequate reliability across the 18 items (coefficient alpha $=.89$ ) and so used the mean across all items in our analyses. The Memory Controllability Inventory (MCI; Lachman et al., 1995) was used to measure beliefs pertaining to memory ability and the extent to which it is perceived as controllable. The MCI, containing four subscales with a total of 20 items, has been shown to be predictive of subsequent recall performance (Lachman et al., 1995). The four subscales formed a reliable memory controllability scale (coefficient alpha $=.80$ ), enabling us to use the average of the means of the subscales in our analyses.

Finally, we included four sets of ratings pertaining to the reading task. The participants rated their level of enjoyment, interest, effort, and engagement in each passage immediately after completing the reading task. A factor analysis indicated that interest and enjoyment ratings formed one factor, whereas effort and engagement ratings formed another. We therefore took the mean across the first two types of ratings (coefficient alpha $=.84$ ) and the last two types (coefficient alpha $=.87$ ) to form composites of interest/enjoyment and effort/engagement, respectively.

\section{Procedure}

The participants were tested individually in a session lasting between 1.5 and $2 \mathrm{~h}$. Sessions began with the administration of the NFC, MCI, and vocabulary test, followed by the reading task (including recall and ratings), and ended with the WM span task.

All participants received all six passages, three in the fullattention condition and three in the divided-attention condition to be described. The full- and divided-attention conditions were blocked with half of the participants in each age and knowledge group having the full-attention condition first and half having the dividedattention condition first. The passages presented in each condition were counterbalanced across participants such that, by the end of the experiment, each passage appeared an equal number of times in each condition.
Reading and recall task. Passages were presented on a computer screen clause by clause using DirectRT 2004 (Empirisoft). The participants read at their own pace by pressing the computer keyboard space bar with the dominant hand. With every keypress, the text segment on the screen was replaced with the next text segment. Passages began with a plus sign $(+)$ to signal where the first word of the clause would appear and ended with "The End" followed by a prompt to recall as much as possible out loud into a microphone. Recall was recorded for later transcription and coding. The participants were asked to read at a comfortable pace that would enable them to recall the passage immediately after reading it.

After reading and recalling all of the passages, the participants indicated on a scale of 1 (low) to 5 (high) the extent to which they were interested in, enjoyed, applied effort to, and were engaged in reading each of the passages. Rating scales were presented on the computer screen along with the passage to aid memory for the passage being rated. The participants responded by pressing number keys on the computer keyboard.

Distractor (auditory click) task. In the divided-attention condition, as the participants read the passages, they were also instructed to press a marked key with the index finger of the nondominant hand on hearing a click presented over headphones. (This allowed the participants' dominant hand to be free for the primary task that required them to press the space bar to advance the text.)

The clicks were randomly assigned to text segments with the following restrictions: Two clicks were presented in the first third of the passage, three clicks were presented in the second third of the passage, and three clicks were presented in the last third of the passage, for a total of eight clicks per passage. There were three passages in the divided-attention condition, yielding a total of 24 click trials per participant. When click sounds were presented, they occurred concurrently with the onset of the segment presentation. Because clicks were tied to specific segments within each passage, the participants heard clicks in the same relative distribution across passages regardless of reading rate. The participants were told that their primary task was to read the passages so that they could recall them but also to respond to the clicks as quickly as possible.

In addition to the divided-attention condition, there was a control condition in which the participants performed the click detection task by itself. There were four practice trials and 18 test trials in this control condition.

\section{RESULTS}

We begin our analyses with the two components of reading efficiency: reading times, followed by memory performance. We then present the findings on these two factors in terms of reading efficiency. For all three analyses, we 
used a 2 (title: absent, present) $\times 2$ (WM span group: low, high) $\times 3$ (age: young, middle, old) $\times 2$ (attention condition: full, divided) mixed-design ANOVA, with attention condition as a repeated measure. Because age and WM span can covary, we followed up the age-group analyses on reading efficiency with regressions analyses to aid in the interpretation of potential age and WM span effects.

\section{Reading Times}

Excessively long clause reading times, defined as those that were greater than $4 S D$ above the mean for that individual, were replaced with the upper $4 S D$ limit, affecting $0.6 \%$ of the data. We adopted this relatively loose criterion rather than a more conventional $3 S D$ cutoff, to enable us to conservatively distinguish between meaningful response times and those that reflected nonreading activities, such as coughs or eyeglass adjustments. A median reading time for each passage was computed for each participant, and these were averaged across passages within full- and divided-attention conditions. These data are shown in the top half of Table 2 . There was a main effect of age $[F(2,277)=4.96, p<.01]$, reflecting the finding that older adults read more slowly than did younger adults $\left(M_{\mathrm{y}}=1,551 \mathrm{msec}, S D_{\mathrm{y}}=648 ; M_{\mathrm{m}}=1,721 \mathrm{msec}\right.$, $\left.S D_{\mathrm{m}}=599 ; M_{\mathrm{o}}=1,882 \mathrm{msec}, S D_{\mathrm{o}}=930\right)$, and a main effect of title $[F(1,277)=6.01, p<.05]$, indicating that the participants in the no-title group $\left(M_{\mathrm{nt}}=1,817 \mathrm{msec}\right.$, $\left.S D_{\mathrm{nt}}=786\right)$ read more slowly than did those in the title group $\left(M_{\mathrm{t}}=1,623 \mathrm{msec}, S D_{\mathrm{t}}=707\right)$.

There was an attention condition $\times$ title interaction $[F(1,277)=6.01, p<.05]$, which was qualified by an attention condition $\times$ age $\times$ title $\times$ WM span interaction $[F(2,277)=3.97, p<.05]$. The mean reading times are reported in milliseconds as a function of age, title, WM span, and attention condition in the upper portion of Table 2. The data for younger adults showed that the high WM span participants $\left(M_{\mathrm{y}-\mathrm{hs}}=1,708 \mathrm{msec}, S D_{\mathrm{y}-\mathrm{hs}}=771\right)$ had a tendency to read more slowly than did their low WM span counterparts $\left(M_{\mathrm{y}-\mathrm{ls}}=1,394 \mathrm{msec}, S D_{\mathrm{y}-\mathrm{ls}}=451\right)$, regardless of contextual knowledge and attention condition $[t(96)=2.23, p<.05]$. In contrast, the effect of WM span on reading times was nonsignificant among middle-aged and older readers ( $F<1$ for both age groups). Data among the two older groups appear to be less systematic. For example, among older adults, no-title participants with low WM spans seemed to read more slowly than did those with high WM spans for the single-task condition, but the opposite pattern appeared for the divided-attention condition. These reading times, of course, must be seen within the context below of how much the participants recalled from what they read.

\section{Memory Performance}

Verbal recall was transcribed from audio tapes. Written responses were scored using a gist criterion (Turner \& Greene, 1978); credit was given for recall of propositions containing the gist of the text's original proposition, rather than scoring for verbatim recall. A subset of $10 \%$ of the data from each age group was scored by a second rater. Neither of the raters was told the WM span or condition of the participants they were scoring. Correlations between scores from the two raters ranged between .90 and .96 , indicating that this method of scoring was reliable. Due to equipment or experimenter error, partial recall data were lost for 1 younger participant and 1 middle-aged participant. In addition, 2 middle-aged adults failed to recall any propositions from passages within either the full- or the divided-attention condition. The participants with missing data $(n=2)$ and those who were unable to recall propositions from any of the three passages within one condition $(n=2)$ were removed from the recall and reading efficiency analyses.

The mean proportion of propositions recalled for both attention conditions within age and title groups is shown in the lower portion of Table 2 . We found a main effect of attention condition $[F(1,277)=15.34, p<.001]$, confirming that recall was higher for texts read under full-attention $\left(M_{\mathrm{fa}}=.21, S D_{\mathrm{fa}}=.12\right)$ relative to divided-attention $\left(M_{\mathrm{da}}=\right.$ $\left..19, S D_{\mathrm{da}}=.12\right)$ conditions. There were also main effects of age $\left[F(2,277)=14.90, p<.001 ; M_{\mathrm{y}}=.24, S D_{\mathrm{y}}=\right.$

Table 2

Means and Standard Deviations of Reading Time and Recall Measures Within Title (Contextual Knowledge), WM Span, and Age Groups

\begin{tabular}{|c|c|c|c|c|c|c|c|c|c|c|c|c|c|}
\hline & & \multicolumn{6}{|c|}{ No Title (No Contextual Knowledge) } & \multicolumn{6}{|c|}{ Title (Contextual Knowledge) } \\
\hline & & \multicolumn{3}{|c|}{ Low WM Span } & \multicolumn{3}{|c|}{ High WM Span } & \multicolumn{3}{|c|}{ Low WM Span } & \multicolumn{3}{|c|}{ High WM Span } \\
\hline & & Young & Middle & Older & Young & Middle & Older & Young & Middle & Older & Young & Middle & Older \\
\hline \multicolumn{14}{|c|}{ Reading Time } \\
\hline Full attention & $M$ & 1,481 & 2,084 & 1,976 & 1,735 & 1,820 & 2,152 & 1,256 & 1,577 & 1,723 & 1,670 & 1,614 & 1,779 \\
\hline & $S D$ & 413 & 732 & 739 & 611 & 656 & 1,394 & 533 & 540 & 849 & 822 & 627 & 817 \\
\hline Divided attention & $M$ & 1,504 & 1,881 & 2,006 & 1,779 & 1,762 & 1,774 & 1,279 & 1,566 & 1,734 & 1,672 & 1,583 & 1,912 \\
\hline & $S D$ & 434 & 606 & 976 & 716 & 617 & 1,183 & 441 & 527 & 694 & 946 & 553 & 973 \\
\hline \multicolumn{14}{|c|}{ Recall } \\
\hline Full attention & $M$ & .14 & .13 & .11 & .23 & .19 & .14 & .27 & .25 & .21 & .33 & .28 & .26 \\
\hline \multirow{3}{*}{ Divided attention } & $S D$ & .09 & .09 & .07 & .12 & .08 & .09 & .10 & .10 & .12 & .12 & .12 & .09 \\
\hline & $M$ & .13 & .12 & .08 & .21 & .17 & .11 & .27 & .21 & .15 & .33 & .28 & .26 \\
\hline & $S D$ & .10 & .10 & .06 & .12 & .06 & .07 & .11 & .10 & .10 & .14 & .10 & .11 \\
\hline
\end{tabular}

Note-WM, working memory. Reading time is presented as the median clause reading time (in milliseconds) for a passage, averaged across passages; recall is presented as the proportion of idea units (propositions) recalled per passage, averaged across passages. 
$\left..13 ; M_{\mathrm{m}}=.21, S D_{\mathrm{m}}=.10 ; M_{\mathrm{o}}=.16, S D_{\mathrm{o}}=.10\right]$, title $\left[F(1,277)=99.48, p<.001 ; M_{\mathrm{nt}}=.15, S D_{\mathrm{nt}}=.09 ; M_{\mathrm{t}}=\right.$ $\left..26, S D_{\mathrm{t}}=.11\right]$, and $\mathrm{WM}$ span $[F(1,277)=28.68, p<$ $\left..001 ; M_{\mathrm{ls}}=.17, S D_{\mathrm{ls}}=.11 ; M_{\mathrm{hs}}=.23, S D_{\mathrm{hs}}=.12\right]$, all in the expected directions. There was also a significant attention condition $\times$ title $\times \mathrm{WM}$ span interaction $[F(1,277)=$ $6.60, p<.05]$. As can be seen in the lower portion of Table 2, the no-title low WM span group, the no-title high WM span group, and the title low WM span group each recalled less in the divided-attention condition relative to the full-attention condition ( $p<.02$, for all three $t$ tests). However, the title high WM span participants recalled essentially the same amount for both attention conditions $(t<1)$. No other interactions were significant.

\section{Reading Efficiency}

For each participant, reading efficiency was computed separately for each passage by dividing the median clause reading time by the number of propositions recalled for that passage. We then computed an efficiency summary variable for each reading condition by averaging across the three passages within each condition. The participants with an outlier on either efficiency variable that was $3 S D$ above the mean (indicating very large amounts of time per unit of recall) within their respective age, title, and WM span group were removed from the analysis. This resulted in the loss of 2 younger, 3 middle-aged, and 1 older adult.

Figure 1 shows mean reading efficiency (time in milliseconds per proposition recalled; msec/prop) for the title and no-title groups and high and low WM span groups, within the young, middle-aged, and older groups for the full-attention (left panels) and divided-attention (right panels) conditions. In this calculation, lower scores represent greater reading efficiency. Consistent with our prediction, we found a main effect of title $[F(1,277)=$ $124.45, p<.001]$, such that those given passage titles $\left(M_{\mathrm{t}}=178 \mathrm{msec} / \mathrm{prop}, S D_{\mathrm{t}}=119\right)$ were more efficient than were those without titles $\left(M_{\mathrm{nt}}=426 \mathrm{msec} / \mathrm{prop}\right.$, $\left.S D_{\mathrm{nt}}=304\right)$. In addition, we found a main effect of
Full Attention

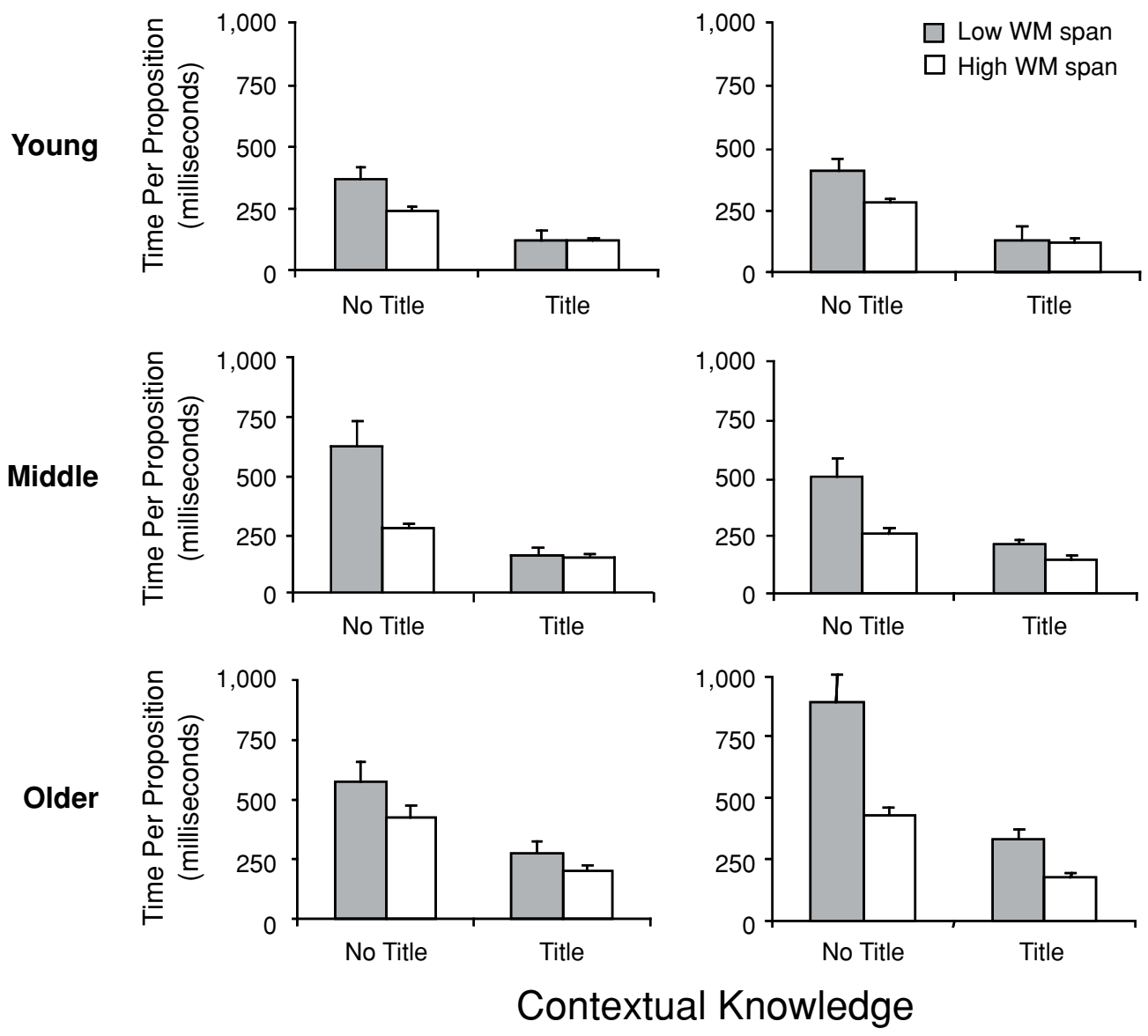

Figure 1. Reading time (in milliseconds) per proposition recalled for young, middle-aged, and older adults, with passage titles (contextual knowledge) and without passage titles (no contextual knowledge), for the full-attention and divided-attention conditions. Lower bars (shorter reading times per proposition recalled) represent greater reading efficiency. 
WM span $[F(1,277)=40.35, p<.001]$, showing that the high WM span participants $\left(M_{\mathrm{hs}}=237 \mathrm{msec} / \mathrm{prop}\right.$, $\left.S D_{\mathrm{hs}}=160\right)$ were more efficient than were the low WM span participants $\left(M_{\mathrm{ls}}=377 \mathrm{msec} / \mathrm{prop}, S D_{\mathrm{ls}}=328\right)$. We also found a main effect of age $[F(2,277)=22.89, p<$ $.001]$, indicating that younger adults $\left(M_{\mathrm{y}}=228 \mathrm{msec} /\right.$ prop, $\left.S D_{\mathrm{y}}=182\right)$ were more efficient readers than were middle-aged adults $\left(M_{\mathrm{m}}=272 \mathrm{msec} / \mathrm{prop}, S D_{\mathrm{m}}=237\right)$, who in turn were more efficient than were older adults $\left(M_{\mathrm{o}}=401 \mathrm{msec} / \mathrm{prop}, S D_{\mathrm{o}}=314\right)$. The main effect of attention condition failed to reach significance $[F(1,277)=$ $2.67, p=.10]$. The means, however, were in the expected direction in that the participants in the full-attention condition $\left(M_{\mathrm{fa}}=290 \mathrm{msec} / \mathrm{prop}, S D_{\mathrm{fa}}=268\right)$ read more efficiently than did those in the divided-attention condition $\left(M_{\mathrm{da}}=315 \mathrm{msec} / \mathrm{prop}, S D_{\mathrm{da}}=317\right)$.

As can be seen in the summary of ANOVA effects presented in Table 3, in addition to main effects of age, title, and WM span, there were a number of two- and three-way interactions. Relevant to our prediction was the significant title $\times$ WM span interaction $[F(2,277)=16.64, p<$ $.001]$, suggesting that the difference between the low WM span participants $\left(M_{\mathrm{ls}}=550 \mathrm{msec} / \mathrm{prop}, S D_{\mathrm{ls}}=372\right)$ and the high WM span participants $\left(M_{\mathrm{hs}}=321 \mathrm{msec} / \mathrm{prop}\right.$, $\left.S D_{\mathrm{hs}}=174\right)$ without contextual knowledge was greater $[t(142)=4.85, p<.001]$ than was the difference between the low WM span participants $\left(M_{\mathrm{ls}}=209 \mathrm{msec} / \mathrm{prop}\right.$, $\left.S D_{\mathrm{ls}}=146\right)$ and the high WM span participants $\left(M_{\mathrm{hs}}=\right.$ $152 \mathrm{msec} /$ prop, $\left.S D_{\mathrm{hs}}=80\right)$ with contextual knowledge $[t(143)=2.96, p<.01]$.

However, the above interaction was qualified by a significant four-way interaction among title, WM span, age, and attention condition $[F(2,277)=3.37, p<.05]$. As can be seen in the left-hand panel of Figure 1, among the par-

Table 3

Effects for Age $\times$ Title (Contextual Knowledge) $\times$ WM Span $\times$ Attention Condition Repeated Measures ANOVA on Reading Efficiency

\begin{tabular}{|c|c|c|c|}
\hline Source & $d f$ & $F$ & $\eta$ \\
\hline \multicolumn{4}{|c|}{ Between Participants } \\
\hline Age (A) & 2 & $22.88^{* * *}$ & .14 \\
\hline Title (T) & 1 & $124.45^{* * *}$ & .31 \\
\hline WM span (S) & 1 & $40.35^{* * *}$ & .13 \\
\hline $\mathrm{A} \times \mathrm{T}$ & 2 & $2.97^{\dagger}$ & .02 \\
\hline$A \times S$ & 2 & $3.51^{*}$ & .03 \\
\hline $\mathrm{T} \times \mathrm{S}$ & 1 & $16.36^{* * *}$ & .06 \\
\hline $\mathrm{A} \times \mathrm{T} \times \mathrm{S}$ & 2 & $<1.00$ & \\
\hline Error & 277 & & \\
\hline \multicolumn{4}{|c|}{ Within Participants } \\
\hline Attention condition (AC) & 1 & $2.67^{\dagger}$ & .01 \\
\hline $\mathrm{AC} \times \mathrm{A}$ & 2 & $7.07^{* *}$ & .03 \\
\hline $\mathrm{AC} \times \mathrm{T}$ & 1 & $<1.00$ & \\
\hline $\mathrm{AC} \times \mathrm{S}$ & 1 & $1.93^{\dagger}$ & .01 \\
\hline $\mathrm{AC} \times \mathrm{A} \times \mathrm{T}$ & 2 & $5.37^{*}$ & .03 \\
\hline $\mathrm{AC} \times \mathrm{A} \times \mathrm{S}$ & 2 & $5.42^{* *}$ & .04 \\
\hline $\mathrm{AC} \times \mathrm{T} \times \mathrm{S}$ & 1 & $<1.00$ & \\
\hline $\mathrm{AC} \times \mathrm{A} \times \mathrm{T} \times \mathrm{S}$ & 2 & $3.03^{*}$ & .02 \\
\hline $\mathrm{AC}$ error & 277 & & \\
\hline
\end{tabular}

ticipants who received passage titles in the full-attention condition, the efficiency of high WM span and low WM span groups was comparable for young $(t<1)$, middleaged $(t<1)$, and older $[t(47)=1.40, p>.10]$ adults. However, among the no-title participants in the dividedattention condition (see right-hand panel of Figure 1), the WM span group differences depended on age group. Although, in the title condition, WM span was not associated with greater reading efficiency for younger adults $(t<1)$, it was associated with greater efficiency for middle-aged adults $(p<.05)$ and older adults $(p<.001)$.

To summarize the results of the ANOVA, the title $\times$ WM span interaction is consistent with the prediction that WM span is less important when readers can draw on contextual knowledge. The significant four-way interaction suggests that this pattern is exaggerated for middle-aged and older adults in the divided-attention condition relative to in the full-attention condition. In fact, among younger adults in either attention condition, contextual knowledge compensated fully for reduced WM span. However, when middle-aged and older adults read under divided-attention conditions, WM span provided additional efficiency benefits over and above those provided by knowledge.

\section{Regression Analyses}

The above ANOVA relied on a median split of WM span that was computed separately for each age group. This was done in order to maintain the natural variability in WM span that occurs with age. However, a drawback of this approach is that there is an inherently unequal distribution of WM spans within the young, middle-aged, and older adults, such that, for example, some high WM span older adults will be comparable to some low WM span younger adults. In consequence, group analyses, although important, make it difficult to interpret the joint effects of age and WM span on reading efficiency. In order to further examine effects of age and WM span, we conducted two hierarchical linear regressions: one predicting reading efficiency under full-attention conditions, and another predicting reading efficiency under divided-attention conditions. In these analyses, age and WM span were treated as continuous variables rather than as categorical. We computed four interaction terms: age $\times$ title, title $\times$ WM span, age $\times$ WM span, and age $\times$ title $\times$ WM span. In the first step, we entered the main effects of age, title, and WM span. In the second step, we entered the three two-way interactions. In the last step, we entered the three-way interaction. For both regression analyses, the main effects of age, title, and WM span were significant for full attention [age, $t(285)=$ 2.8, $S E=0.8$; title, $t(285)=8.8, S E=26.7$; WM span, $t(285)=4.6, S E=9.3$ ] and for divided attention [age, $t(285)=3.3, S E=0.9$; title, $t(285)=8.3, S E=31.5$; WM span, $t(285)=4.9, S E=11.0, p<.01]$.

The interaction terms were the focus of these analyses. For the full-attention condition, we found a significant title $\times$ WM span interaction $[t(282)=2.5, S E=18.7$, $p<.05]$, showing greater differences in reading efficiency between high WM span participants relative to low WM span participants among those who did not have 
titles, but we found no differences in reading efficiency between high and low WM span participants among those who had passage titles. For the regression predicting reading efficiency in the divided-attention condition, we also found a significant title $\times$ WM span interaction $[t(282)=$ 2.3, $S E=21.8, p<.05]$, showing a pattern similar to that found in the full-attention analysis. For the dividedattention analysis, we also found a significant age $\times \mathrm{WM}$ span coefficient $[t(282)=3.0, S E=0.6, p<.01]$, showing that there was no age decrement in reading efficiency among high WM span participants, but there was an age decrement among low WM span participants. No other interaction terms were significant.

To summarize the results of the regression analyses, the data showed that the title $\times$ WM span effects were consistent with those based on the ANOVA - namely, that the advantages of WM span were diminished when the participants had contextual knowledge. These findings suggest that contextual knowledge reduced demands on WM. The regressions further clarified that this was true for both attention conditions. The regressions also helped to clarify the joint effects of WM span and age. Specifically, the regressions made it clear that WM span contributed little to reading efficiency among younger adults in the divided-attention condition, but it contributed significantly to reading efficiency among older adults.

\section{Distractor Task}

Median response times (RTs) for the single (click task alone) and dual (click task while reading) conditions of the distractor task were calculated for each participant. The participants with RTs on either variable (single or dual) that were $3 S D$ above the mean for each age, title, and WM span group were removed. This resulted in the loss of 2 younger and 4 middle-aged adults. RTs were analyzed in a 2 (title: absent, present) $\times 2$ (WM span group: low, high) $\times 3$ (age: young, middle, old) $\times 2$ (attention condition: single, dual) mixed-design ANOVA, with attention condition as a repeated measure.

As might be expected, there was a main effect of attention condition $[F(1,282)=1,713.70, p<.001]$, showing that RTs to clicks were faster in the single-attention control condition without concurrent reading than in the dual-attention condition. There was also a main effect of age $[F(2,282)=16.80, p<.001]$, showing an age-related increase in RTs to the clicks $\left(M_{\mathrm{y}}=328 \mathrm{msec}, S D_{\mathrm{y}}=82\right.$; $\left.M_{\mathrm{m}}=340 \mathrm{msec}, S D_{\mathrm{m}}=57 ; M_{\mathrm{o}}=385 \mathrm{msec}, S D_{\mathrm{o}}=78\right)$. A main effect of title $[F(1,282)=5.38, p<.05]$ was qualified by an attention condition $\times$ title interaction $[F(1,282)=4.48, p<.05]$. This interaction was based on faster RTs of the title group $\left(M_{\mathrm{t}}=459 \mathrm{msec}, S D_{\mathrm{t}}=106\right)$ relative to the no-title group $\left(M_{\mathrm{nt}}=490 \mathrm{msec}, S D_{\mathrm{nt}}=\right.$ $137)$ in the dual-attention condition $[t(292)=2.14, p<$ .05] but comparable RTs of the title and no-title groups $\left(M_{\mathrm{t}}=224 \mathrm{msec}, S D_{\mathrm{t}}=46 ; M_{\mathrm{nt}}=231 \mathrm{msec}, S D_{\mathrm{nt}}=53\right)$ in the single-attention condition $[t(292)=1.27$, n.s. $]$. A nonsignificant main effect of WM $\operatorname{span}[F(1,282)=$ $2.34, p>.10]$ was qualified by significant attention condition $\times$ age $\times$ WM span interaction $[F(2,282)=4.37$, $p<.05]$. This interaction appears to have been due to a greater impact of dividing attention among older adults with low WM spans relative to the other groups: Among low WM span participants, the differences in RTs between the two attention conditions were 104, 119, and $164 \mathrm{msec}$ for young, middle-aged, and older adults, respectively; among high WM span individuals, the differences in RTs between the two attention conditions were 107, 117, and $128 \mathrm{msec}$ for young, middle-aged, and older adults, respectively. No other interactions were significant.

\section{Structural Equation Model of Motivational and Cognitive Predictors of Reading Efficiency}

For the final analysis, we were interested in obtaining a more comprehensive picture of reading efficiency by assessing the effects of the previously described motivational and cognitive predictors. To do this, we used structural equation modeling to determine the relative predictive strengths of contextual knowledge, WM span, age, need for cognition (NFC), memory beliefs (MCI), interest/enjoyment, and effort/engagement. This approach enabled us to estimate a latent construct of reading efficiency, which, because error is estimated for the construct, allows for a more powerful assessment of predictors than would a multiple hierarchical regression approach.

Prior to running the model, we computed zero-order correlations among the predictor variables and reading efficiency. These correlations are presented in Table 4, where one can see that the correlation between each predictor and reading efficiency was significant. As also seen in Table 4, there were several significant correlations among the predictors themselves. The variables that were significantly correlated with each other were allowed to covary in the structural equation model.

We then tested the fit of a model in which the dependent variable was a latent construct of reading efficiency based on the six estimates of reading efficiency (i.e., for each passage, referred to as "Psg 1 effic" through "Psg 6 effic" in Figure 2), regardless of reading condition. Our goal was to determine whether motivational factors would predict reading efficiency when contextual knowledge, WM span, and age were also taken into account. Therefore, NFC, $\mathrm{MCI}$, interest/enjoyment, and effort/engagement were considered simultaneously with knowledge, WM span, and age. We tested the model using Amos 5 structural equations software and found a good fit to the data when all paths between predictors and the outcome were allowed to be estimated freely $\left[\chi^{2}(57)=77.9, p<.05\right.$, comparative fit index $(\mathrm{CFI})=.97$, and root mean square error of approximation $(\mathrm{RMSEA})=.04]$.

The path diagram presented in Figure 2 contains the standardized path coefficients for each predictor; solid lines denote significant paths, whereas dashed lines denote nonsignificant paths. Double-headed arrows signify paths between predictors that were allowed to covary because they were significantly correlated with each other, as indicated in Table 4. As shown in Figure 2, each estimate of reading efficiency significantly loaded on the latent construct of reading efficiency. In addition, contex- 
Table 4

Correlations Among Contextual Knowledge, WM Span,

Age, Motivational Predictors, and Reading Efficiency

\begin{tabular}{|c|c|c|c|c|c|c|c|}
\hline & $\begin{array}{l}\text { Reading } \\
\text { Efficiency }\end{array}$ & $\begin{array}{l}\text { Contextual } \\
\text { Knowledge }\end{array}$ & $\begin{array}{l}\text { WM } \\
\text { Span }\end{array}$ & Age & NFC & MCI & $\begin{array}{c}\text { Effort/ } \\
\text { Engagement }\end{array}$ \\
\hline Contextual knowledge & $.47^{* * *}$ & & & & & & \\
\hline WM span & $.33^{* * *}$ & -.01 & & & & & \\
\hline Age & $-.27^{* * *}$ & -.01 & $-.32^{* * *}$ & & & & \\
\hline NFC & $.19^{* * *}$ & .03 & $.23^{* * *}$ & $-.20^{* * *}$ & & & \\
\hline MCI & $.13^{*}$ & .06 & .11 & -.02 & $.36^{* * *}$ & & \\
\hline Effort/engagement & $.12^{*}$ & .06 & .00 & .00 & .10 & .06 & \\
\hline Interest/enjoyment & $.32^{* * *}$ & $.29^{* * *}$ & .09 & -.08 & $.16^{* *}$ & $.18^{* *}$ & $.28^{* * *}$ \\
\hline
\end{tabular}

tual knowledge, WM span, age, and interest/enjoyment significantly predicted reading efficiency. However, NFC, $\mathrm{MCI}$, and effort/engagement failed to predict reading efficiency after controlling for contextual knowledge, WM span, and age.

We contrasted our hypothesized model with one in which the paths from contextual knowledge and WM to the outcome were constrained to be equal $\left[\chi^{2}(58)=125.5, p<\right.$ $.001, \mathrm{CFI}=.89, \mathrm{RMSEA}=.06]$, as well as one in which the paths from contextual knowledge and age to the outcome were constrained to be equal $\left[\chi^{2}(58)=154.4, p<\right.$ $.001, \mathrm{CFI}=.85, \mathrm{RMSEA}=.08]$. In both cases, there was a reduction in the fit of model to the data $\left(\chi^{2}\right.$ difference tests; $p<.001$ ), suggesting that contextual knowledge was a stronger predictor than were age and WM. Finally, we tested a fourth model in which the paths from WM and age to the outcome were constrained to be equal. Although the fit $\left[\chi^{2}(58)=106.9, p<.001, \mathrm{CFI}=.92, \mathrm{RMSEA}=\right.$
$.05]$ was reduced relative to our original model $\left(\chi^{2}\right.$ difference test; $p<.001$ ), this model still fit the data relatively well, suggesting that age and WM had effects on reading efficiency that were comparable in magnitude.

\section{DISCUSSION}

The data from the present study are consistent with our hypothesis that readers who are able to access relevant knowledge while reading make trade-offs between reading speed and memory trace quality, which result in greater reading efficiency (see also Carver, 1990). We argue that due to speed-accuracy trade-offs during reading, independent measures of reading time and recall do not provide a full picture of the effects of knowledge on reading. In the present study, we found that readers without contextual knowledge and older readers - two groups that showed relatively poor memory performance-read more slowly

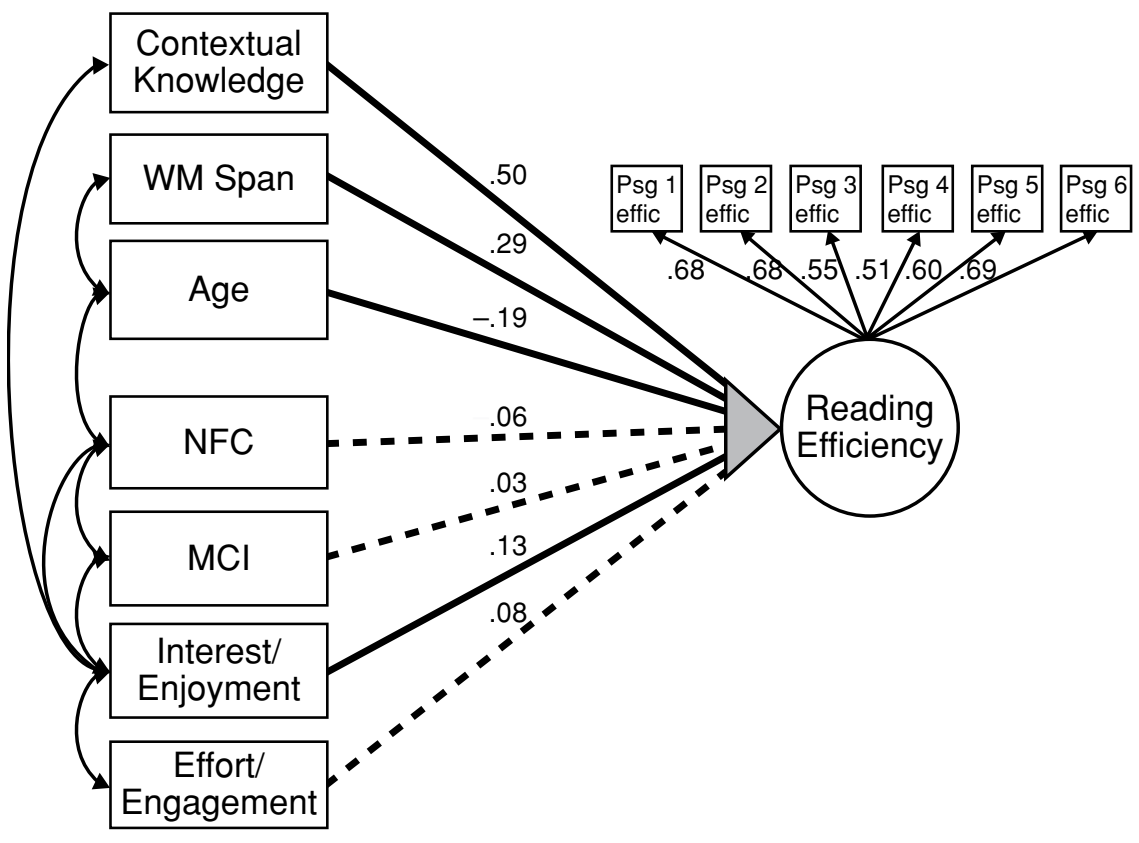

Figure 2. Path diagram depicting predictors of reading efficiency. Solid lines denote significant paths. Double-headed arrows signify predictors significantly correlated with each other. 
than did those with such knowledge and younger readers. However, high WM span younger adults, who had strong memory performance, also read more slowly than did their low WM span counterparts. These findings imply that longer reading times can reflect time well spent (e.g., high WM span younger readers who recalled the text well) or indicate time spent floundering (e.g., readers without access to contextual knowledge who recalled the text poorly) and may provide one reason why encoding time and performance may not be correlated within reading tasks (e.g., Walker et al., 1983) and other cognitive tasks (e.g., Mazzoni \& Cornoldi, 1993).

Although individuals without prior contextual knowledge also make trade-offs, their extra time reading is less likely to yield increases in memory performance. The positive effects of passage titles on reading efficiency may lie in the ability of contextual knowledge to guide several text processes - for example, the ability to identify the appropriate meanings of words, organize and integrate concepts, generate appropriate inferences, and construct effective retrieval structures. These processes in turn serve to augment memory performance (Chi, Glaser, \& Farr, 1988; Ericsson \& Kintsch, 1995; Spilich et al., 1979). Those not having the advanced knowledge supplied by the title, on the other hand, may make errors accessing the meanings of ambiguous words, connect propositions incorrectly, and, in general, fail to construct a coherent representation of the text. In this article, we argue that, by making these tasks more efficient, knowledge should also reduce demands on WM.

\section{Contextual Knowledge Reduces Demands on Working Memory}

We hypothesized that contextual knowledge would make reading more efficient and further that these benefits of knowledge should be evident in reduced reliance on WM during reading. Support for this notion was found in the present study. We found that WM span was less important among the participants who received passage titles than among those who did not. Specifically, differences between high and low WM span groups were smaller among the participants who had access to contextual knowledge prior to reading than among those who did not. The conclusion that contextual knowledge reduces demands on WM was further supported by the regression analyses. These findings suggest that, when reading without the benefit of contextual knowledge, individuals rely relatively more on WM to perform text processes, such as identifying appropriate word meanings, attempting to organize and integrate vague concepts, and creating a situation model that is consistent with the text. A larger WM capacity enables people to cope better with this challenge because these individuals are (1) able to hold and manipulate a greater number of fragmented pieces of information at one time and (2) able to apply more effective reading strategies (Just \& Carpenter, 1992).

The notion that contextual knowledge reduces demands on WM during reading was further supported by the finding that the benefits of contextual knowledge (i.e., differences in reading efficiency between no-title and title conditions) were greatest among the two older age groups, for the divided-attention reading condition, and for both factors combined. That is, both age and the requirement of dividing attention created conditions under which available WM was reduced and knowledge became more important.

We also found that the participants with contextual knowledge were able to respond faster to the distractor task in the divided-attention condition than were those without this prior knowledge. This finding is consistent with the notion that prior knowledge reduces the necessary draw on WM capacity during reading, enabling more cognitive resources to be directed toward the distractor task than when such knowledge is lacking. This particular finding is interesting in view of Britton, Holdredge, Curry, and Westbrook's (1979) study using a whole-text presentation. In contrast to what we found, Britton et al. found that readers with prior contextual knowledge (provided by passage titles) were slower to respond to clicks than were those without this knowledge. However, Britton et al.'s wholetext presentation method may have allowed participants to reread sections of the text, which could have reduced the difficulty of the no-title condition (Inhoff \& Fleming, 1989) and thus could account for some of the differences between Britton et al.'s results and our own.

In general, the findings from the present study demonstrate that knowledge makes reading more efficient by reducing demands on WM. These findings may help to explain why knowledge can appear to compensate for limitations in a variety of cognitive domains (Adams et al., 1995; West et al., 1995), including, in the present case, WM. Research within the area of cognitive aging has also demonstrated that expertise (extensive experience within a domain that is often accompanied by a rich knowledge base) may be particularly advantageous to older adults who have decreased WM capacities (e.g., Clancy \& Hoyer, 1994; Morrow et al., 1994). In addition, our data are consistent with data from work on aviation expertise showing that the role of WM decreased as skilled aviation performance increased on a domain-specific memory task (Sohn \& Doane, 2003).

\section{Generalizability of Present Findings}

One could argue that not having a passage title in this study is a somewhat extreme case of absence of knowledge. However, even without the passage titles, the passages still had meaning (e.g., relative to passages with scrambled word or sentence order). This was enough so that no-title readers seemed compelled to find meaning rather than give up. The situation that these readers experienced may be similar to the previously described case of beginning a text in midsection when in the waiting room of a physician's office. In this example, the reader needs to work harder at constructing a meaningful representation. However, even after allocating this extra time, he/she may not fully comprehend the excerpted text. Importantly, our data suggest that individuals faced with this situation who have larger WM capacities will fare better than those with smaller WM capacities. 
The data from the present study are also consistent with the data from two other studies that used a passage title manipulation and also measured both reading times and memory performance (Smith \& Swinney, 1992; Wiley \& Rayner, 2000). Both Smith and Swinney (1992) and Wiley and Rayner (2000) found faster reading times and better recall for the title group relative to the no-title group. Although both studies differed from the present study in that they did not instruct readers to read for recall but rather provided a surprise recall task at the end of the reading task (see, e.g., Aaronson \& Scarborough, 1976, for a discussion on how reading goals affect text processing), our findings are congruent with theirs. Importantly, however, our findings add to the previous findings by showing that contextual knowledge yields a more favorable return on invested time and reduces demands on WM.

Although we argue that the present data do generalize to other situations dealing with the effects of contextual and schematic knowledge, we also assert that knowledge may not always make reading faster (even though it may make reading more efficient). There is evidence to suggest that readers who have an extensive knowledge base within a domain may actually spend more time, relative to low-knowledge individuals, performing conceptual integration when reading in this domain (Miller, 2001, 2003; Miller et al., 2004). In these cases, the authors have argued that readers who have an extensive knowledge base take more time in order to fully instantiate meanings of complex constructs and to organize and integrate these ideas with a rich knowledge base. For this reason, one might not necessarily expect the present findings to generalize to all other types of knowledge, such as the effects of familiarity on reading and recall (Kaakinen et al., 2003) or the effects of baseball knowledge on memory for spoken baseball narratives (Hambrick \& Engle, 2002).

We have a final caution. Although the measure we used (Daneman \& Carpenter, 1980) is commonly used in the reading literature, it is a measure of WM that is potentially influenced by strategy (McNamara \& Scott, 2001) and it is a measure that relies on reading itself. This raises the question, not addressed in the present study, of whether WM should be considered a domain-free capacity or whether there may be some independence between verbal WM and other potential WM domains (e.g., Carpenter, Miyake, \& Just, 1994, p. 1079).

\section{Motivational and Cognitive Predictors of Reading Efficiency}

Using structural equation modeling, we assessed the ability of both motivational and cognitive factors to predict reading efficiency. The cognitive predictors of knowledge, age, and WM span were entered simultaneously with motivational factors. For motivational factors, we focused on two distal indices of general cognitive engagement (need for cognition) and memory controllability beliefs, as well as two more proximal measures: passage interest and effort related to the task (see also Guthrie \& Wigfield, 1999). Correlational analyses showed that all of the cognitive and motivational factors were significantly related to reading efficiency. Specifically, access to contextual knowledge, younger age, and larger WM spans were associated with greater reading efficiency. In addition, need for cognition, level of memory controllability beliefs, passage interest, and self-reported effort were also positively associated with reading efficiency.

We first note that the structural equation model showed that reading efficiency formed a reliable latent construct, suggesting that our operationalization of reading efficiency is psychometrically sound. Second, the hypothesized model and supporting models showed that knowledge was the strongest predictor of reading efficiency even after controlling for age, WM span, need for cognition, memory controllability, interest, and self-reported effort. This finding is consistent with our notion that contextual knowledge makes reading more efficient and further suggests that contextual knowledge is more powerful than is WM capacity. This is a critical finding given that WM has been shown to be important for language tasks (Daneman \& Merikle, 1996; Just \& Carpenter, 1992). It is also important to note that self-reported passage interest was the only motivational predictor that remained significant. The finding that interest is an important correlate of reading comprehension has been demonstrated in the past (e.g., Lin et al., 1997; Schiefele \& Krapp, 1996). However, neither interest nor the influences of age and WM span were comparable to knowledge in its ability to predict reading efficiency.

\section{Conclusions}

In a previous paper (Miller \& Stine-Morrow, 1998), we showed that contextual knowledge reduces the time readers spend on reading, with the benefits of knowledge most pronounced among high-recalling older adults relative to younger adults. In particular, we showed that contextual knowledge affected reading strategies, such that participants given passage titles spent considerably less time performing conceptual integration than did participants not given the passage title. In the present study, we reaffirmed that contextual knowledge facilitates reading, but added to those data in two ways. First, we showed that readers with prior knowledge had more favorable returns on their invested time (i.e., were more efficient readers). Second, we replicated the finding that knowledge is particularly helpful to older adults (Miller \& Stine-Morrow, 1998), and we demonstrated that one reason why knowledge may be especially beneficial to older adults is that it reduces demands on WM capacity.

It is certainly the case that, on average, WM capacity declines with age. Indeed, one might argue that this association is so close that WM and age represent essentially the same construct. This is not necessarily a claim we wish to make. Rather, what our present results indicate is that, under conditions in which WM capacity may be limited (e.g., due to attentional demands or the effects of aging), contextual knowledge will play a greater role in how efficiently individuals read in terms of how fast they read and how much they retain. These results give weight to the proposition that, to understand superior reading perfor- 
mance, one must consider the complex interplay between capacity and knowledge and perhaps even motivational influences, such as interest in the passages being read.

\section{REFERENCES}

Aaronson, D., \& Scarborough, H. S. (1976). Performance theories for sentence coding: Some quantitative evidence. Journal of Experimental Psychology: Human Perception \& Performance, 2, 56-70.

Adams, B. C., Bell, L. C., \& Perfetti, C. A. (1995). A trading relationship between reading skill and domain knowledge in children's text comprehension. Discourse Processes, 20, 302-323.

Arbuckle, T. Y., Vanderleck, V. F., Harsany, M., \& Lapidus, S. (1990). Adult age differences in memory in relation to availability and accessibility of knowledge-based schemas. Journal of Experimental Psychology: Learning, Memory, \& Cognition, 16, 305-315.

BadDeley, A. D., \& Hitch, G. J. (1974). Working memory. In G. H. Bower (Ed.), The psychology of learning and motivation (Vol. 8 , pp. 47-90). New York: Academic Press.

Bransford, J., \& Johnson, M. (1972). Contextual prerequisites for understanding: Some investigations of comprehension and recall. Journal of Verbal Learning \& Verbal Behavior, 11, 717-726.

Britton, B. K., Holdredge, T. S., Curry, C., \& Westbrook, R. (1979). Use of cognitive capacity in reading identical texts with different amounts of discourse level meaning. Journal of Experimental Psychology: Human Learning \& Memory, 5, 262-270.

Cacioppo, J. T., Petty, R. E., \& KaO, C. F. (1984). The efficient assessment of need for cognition. Journal of Personality Assessment, 48, 306-307.

Carpenter, P., Miyake, A., \& Just, M. (1994). Working memory constraints in comprehension. In M. A. Gernsbacher (Ed.), Handbook of psycholinguistics (pp. 1075-1115). New York: Academic Press.

CARVER, R. P. (1990). Reading rate: A review of research and theory. San Diego: Academic Press.

Chi, M., Glaser, R., \& Farr, M. J. (1988). The nature of expertise. Hillsdale, NJ: Erlbaum.

Chiesi, H., SpILICH, G., \& Voss, J. (1979). Acquisition of domain-related information in relation to high and low domain knowledge. Journal of Verbal Learning \& Verbal Behavior, 18, 257-273.

Clancy, S., \& Hoyer, W. (1994). Age and skill in visual search. Developmental Psychology, 30, 545-552.

DANEMAN, M., \& CARPENTER, P. A. (1980). Individual differences in working memory and reading. Journal of Verbal Learning \& Verbal Behavior, 19, 450-466.

Daneman, M., \& Merikle, P. M. (1996). Working memory and language comprehension: A meta-analysis. Psychonomic Bulletin \& Review, 3, 422-433.

Dooling, D. J., \& Lachman, R. (1971). Effects of comprehension on retention of prose. Journal of Experimental Psychology, 88, 216-222.

Dunlosky, J., \& HerTZog, C. (1998). Training programs to improve learning in later adulthood: Helping older adults educate themselves. In D. J. Hacker, J. Dunlosky, \& A. Graesser (Eds.), Metacognition in educational theory and practice (pp. 249-276). Mahwah, NJ: Erlbaum.

Ekstrom, R. B., French, J. W., \& Harman, H. H. (1976). Manual for kit of factor-referenced cognitive tests. Princeton, NJ: Educational Testing Service.

EMPIRISOFT (2004). DirectRT [Computer software]. New York: Author.

ENGLE, R. W. (2001). What is working memory capacity? In H. L. Roediger III, J. S. Nairne, I. Neath, \& A. M. Surprenant (Eds.), The nature of remembering: Essays in honor of Robert G. Crowder (pp. 297314). Washington, DC: American Psychological Association.

ERICSSON, K. A., \& KinTSCH, W. (1995). Long-term working memory. Psychological Review, 102, 211-245.

Gardner, E. T., \& Schumacher, G. M. (1977). Effects of contextual organization on prose retention. Journal of Educational Psychology, 69, 146-151.

Guthrie, J. T., \& Wigfield, A. (1999). How motivation fits into a science of reading. Scientific Studies of Reading, 3, 199-205.

HAMBrick, D. Z., \& ENGLE, R. W. (2002). Effects of domain knowledge, working memory capacity, and age on cognitive performatnce: An investigation of the knowledge-is-power hypothesis. Cognitive Psychology, 44, 339-387.

Hartley, J. T., Stojack, C. C., Mushaney, T. J., Annon, T. A. K., \& LEE, D. W. (1994). Reading speed and prose memory in older and younger adults. Psychology \& Aging, 9, 216-223.

Hultsch, D. F., \& Dixon, R. A. (1983). The role of pre-experimental knowledge in text processing in adulthood. Experimental Aging Research, 9, 17-22.

InHOFF, A. W., \& Fleming, K. (1989). Probe-detection times during the reading of easy and difficult text. Journal of Experimental Psychology: Learning, Memory, \& Cognition, 15, 339-351.

Johnson-Laird, P. (1983). Mental models. Cambridge, MA: Harvard University Press.

Just, M. A., \& CARPenter, P. (1992). A capacity theory of comprehension: Individual differences in working memory. Psychological Review, 99, 122-149.

KaAkinen, J. K., Hyönä, J., \& Keenan, J. M. (2003). How prior knowledge, WMC, and relevance of information affect eye fixations in expository text. Journal of Experimental Psychology: Learning, Memory, \& Cognition, 29, 447-457.

KinTSCH, W. (1994). Text comprehension, memory, and learning. American Psychologist, 49, 294-303.

Lachman, M. E., Bandura, M., Weaver, S. L., \& Elliott, E. (1995). Assessing memory control beliefs: The Memory Controllability Inventory. Aging \& Cognition, 2, 67-84.

Lin, L., ZABrUCKY, K., \& MoOre, D. (1997). The relations among interest, self-assessed comprehension, and comprehension performance in young adults. Reading Research \& Instruction, 36, 127-139.

MAZzonI, G., \& CoRnoldi, C. (1993). Strategies in study time allocation: Why is study time sometimes not effective? Journal of Experimental Psychology: General, 122, 47-60.

McNamara, D. S., \& ScotT, J. L. (2001). Working memory capacity and strategy use. Memory \& Cognition, 29, 10-17.

Means, M. I., \& Voss, J. (1985). Star Wars: A developmental study of expert and novice knowledge structures. Journal of Memory \& Language, 24, 746-757.

Meyer, B. J. F., Talbot, A. P., \& Florencio, D. (1999). Reading rate and prose retrieval. Scientific Studies of Reading, 3, 303-329.

MiLleR, L. M. S. (2001). Effects of real-world knowledge on text processing among older adults. Aging, Neuropsychology, \& Cognition, 8, 137-148.

MiLLER, L. M. S. (2003). The effects of age and domain knowledge on text processing. Journals of Gerontology, 58B, P217-P223.

MilleR, L. M. S., \& GaGNE, D. D. (2005). The effects of age and control beliefs on resource allocation during reading. Aging, Neuropsychology, \& Cognition, 12, 129-148.

Miller, L. M. S., \& Stine-Morrow, E. A. L. (1998). Aging and the effects of knowledge on on-line reading strategies. Journals of Gerontology, 53B, P223-P233.

Miller, L. M. S., Stine-Morrow, E. A. L., Kirkorian, H., \& Conroy, M. (2004). Adult age differences in knowledge-driven reading. Journal of Educational Psychology, 96, 811-821.

MORAVCSIK, J., \& KINTSCH, W. (1993). Writing quality, reading skills, and domain knowledge as factors in text comprehension. Canadian Journal of Experimental Psychology, 47, 360-374.

Morrow, D. G., Leirer, V. O., \& Altieri, P. A. (1992). Aging, expertise, and narrative processing. Psychology \& Aging, 7, 376-388.

Morrow, D. [G.], Leirer, V. [O.], Altieri, P. [A.], \& Fitzsimmons, C. (1994). When expertise reduces age differences in performance. Psychology \& Aging, 9, 134-148.

Rawson, K. A., \& KInTsCh, W. (2002). How does background information improve memory for text content? Memory \& Cognition, 30, 768-778.

Salthouse, T. A. (1991). Theoretical perspectives on cognitive aging. Hillsdale, NJ: Erlbaum.

Schiefele, U., \& Krapp, A. (1996). Topic interest and free recall of expository text. Learning \& Individual Differences, 8, 141-161.

SharkeY, N., \& SHARKEY, A. (1987). What is the point of facilitation? The loci of knowledge-based facilitation in sentence processing. Journal of Memory \& Language, 26, 255-276.

Smith, E. E., \& Swinney, D. A. (1992). The role of schemas in reading text: A real-time examination. Discourse Processes, 15, 303-316. 
Sohn, Y. W., \& Doane, S. M. (2003). Roles of working memory capacity and long-term working memory skill in complex task performance. Memory \& Cognition, 31, 458-466.

SPilich, G., Vesonder, G., Chiesi, H., \& Voss, J. (1979). Text processing of domain-related information for individuals with high and low domain knowledge. Journal of Verbal Learning \& Verbal Behavior, 18, 275-290.

Stine, E. A. L., \& Hindman, J. (1994). Age differences in reading time allocation for propositionally dense sentences. Aging, Neuropsychology, \& Cognition, 1, 2-16.

Stine, E. A. L., Lachman, M., \& Wingfield, A. (1993). The roles of perceived and actual control in memory for spoken language. Educational Gerontology, 19, 331-349.

Summers, W. V., Horton, D. L., \& Diehl, V. A. (1985). Contextual knowledge during encoding influences sentence recognition. Journal of Experimental Psychology: Learning, Memory, \& Cognition, 11, $771-779$

TAYLOR, B. M. (1979). Good and poor readers' recall of familiar and unfamiliar text. Journal of Reading Behavior, 11, 375-380.

Turner, A., \& Greene, F. (1978). Construction and use of a propositional text base. JSAS Catalog of Selected Documents in Psychology, 8(3, MS. no. 1713).
VAN DiJK, T. A., \& KINTSCH, W. (1983). Strategies of discourse comprehension. New York: Academic Press.

Vicente, K. J., \& WANG, J. H. (1998). An ecological theory of expertise effects in memory recall. Psychological Review, 105, 33-57.

Voss, J., Vesonder, G., \& SPILICH, G. (1980). Text generation and recall by high-knowledge and low-knowledge individuals. Journal of Verbal Learning \& Verbal Behavior, 19, 651-667.

Walker, N., Jones, J. P., \& Mar, H. H. (1983). Encoding processes and the recall of text. Memory \& Cognition, 11, 275-282.

West, R. L., Stanovich, K. E., \& Cunningham, A. E. (1995). Compensatory processes in reading. In R. A. Dixon \& L. Bäckman (Eds.), Compensating for psychological deficits and declines: Managing losses and promoting gains (pp. 275-295). Mahwah, NJ: Erlbaum.

WiLEy, J., \& RAYNER, K. (2000). Effects of titles on the processing of text and lexically ambiguous words: Evidence from eye movements. Memory \& Cognition, 28, 1011-1021.

Wingfield, A., Stine, E. A. L., Lahar, C. J., \& Aberdeen, J. S. (1988). Does the capacity of working memory change with age? Experimental Aging Research, 14, 103-107.

(Manuscript received August 24, 2004; revision accepted for publication June 28, 2005.) 